Archive for

Organic Chemistry

Arkivoc 2021, part i, 1-19

\title{
The Bruylants and related reactions
}

\author{
Jean-Marc R. Mattalia \\ Aix-Marseille Univ, CNRS, Centrale Marseille, iSm2, Marseille, France \\ Email: jean-marc.mattalia@univ-amu.fr
}

Received 08-31-2020

Accepted 11-20-2020

Published on line 01-05-2021

\section{Abstract}

This review focuses on the Bruylants reaction, namely the substitution with Grignard reagents of the cyano group in $\alpha$-aminonitriles. This reaction goes through an iminium ion intermediate and proceeds with excellent stereoselectivities. The extension to organozinc reagents has been successfully applied. Triazoles such as benzotriazole and especially 1,2,3-triazole appear as relevant substitutes for the cyano leaving group. An alternative pathway for substitution of the cyano group involves an $\alpha$-alkylation-decyanation sequence. Selected applications in organic synthesis are proposed.

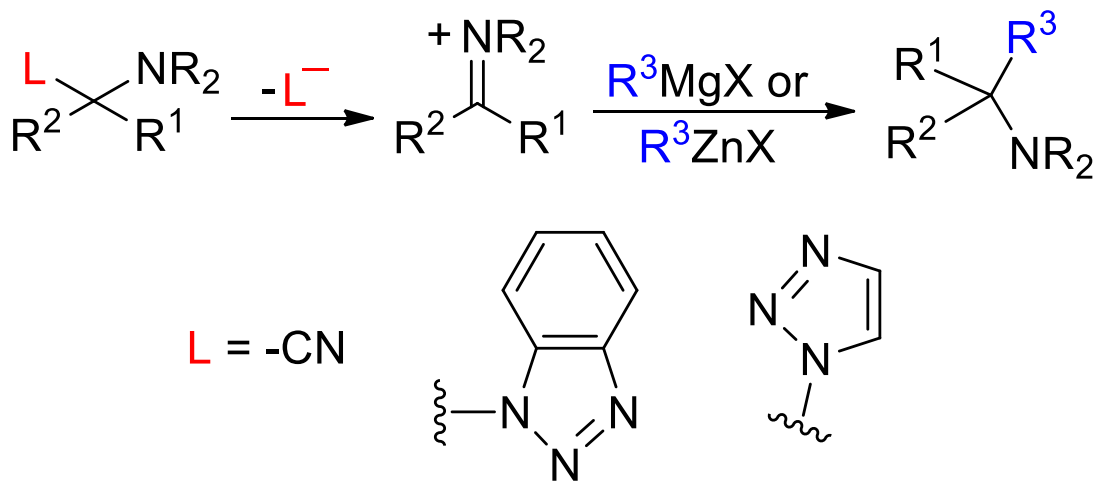

Keywords: $\alpha$-Aminonitrile, iminium ion, Grignard reagent, organozinc, 1,2,3-triazole. 


\section{Table of Contents}

1. Introduction

2. Reactivity of Grignard Reagents towards $\alpha$-Aminonitriles and Chemoselectivity

3. Mechanism Considerations and Iminium Ion Promoters

4. Synthetic Applications

4.1. Enantioselective synthesis of clavepictine analogues

4.2. Dual reactivity of $\alpha$-aminonitriles: Bruylants versus alkylation-decyanation reactions

4.3. Strecker-Bruylants sequence. Intramolecular Bruylants reactions

5. Reactions of $\alpha$ - Aminonitriles with other Organometallic Reagents

6. Alternatives to $\alpha$-Aminonitriles

7. Conclusions

References

\section{Introduction}

The bifunctional $\alpha$-aminonitriles display a rich reactivity and appear as important intermediates in organic synthesis. ${ }^{1}$ Several reviews highlight their role in heterocyclic and natural products chemistry as well as their biological properties. ${ }^{2-7}$ One aspect of their reactivity involves the electrophilic cyano group which is able to react with nucleophiles such as organometallics or hydride donors. On the other hand, they also display nucleophilic properties with the amine function. $\alpha$-Aminonitriles bearing an $\alpha$-hydrogen atom can be deprotonated with strong bases and then attack electrophiles in addition or substitution reactions. ${ }^{8} \alpha-$ Aminonitriles are precursors of iminium ions that react with various nucleophiles. Attack by the hydride ion provides an access to the reductive decyanation product. ${ }^{9,10}$ The iminium intermediates can also react with organometallic reagents. In particular, the reaction with Grignard reagents, discovered by Bruylants in the 1920s, appears widely used in organic synthesis to afford tertiary amine moieties (Scheme 1). ${ }^{11,12}$

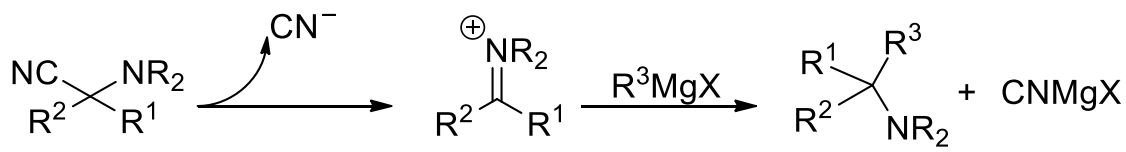

Scheme 1. Bruylants reaction.

This review presents the Bruylants reaction which is already an old transformation - however, over the years improvements as well as new variants have emerged. In the first part, chemoselectivity along with mechanistic considerations are examined. The extension to other leaving groups and organometallic reagents is discussed. Furthermore, synthetic applications aiming to show the usefulness of the Bruylants reaction are proposed.

\section{Reactivity of Grignard Reagents towards $\alpha$-Aminonitriles and Chemoselectivity}

The Bruylants reaction was first described on $N, N$-disubstituted $\alpha$-aminonitriles. ${ }^{11,12}$ Beside the substitution, the reactions of piperidinonitriles with isomers of butylmagnesium chloride afforded other products. ${ }^{13}$ The 
main competing reaction is the normal addition to the cyano group to form an imine and ultimately a carbonyl group. This reaction generally is encountered for $\alpha$-aminonitriles unsubstituted at the $\alpha$-carbon. ${ }^{13-18}$ An example is provided in Scheme 2 on piperidine and pyrrolidine derivatives $\mathbf{1} \mathbf{a}-\mathbf{b} .{ }^{19}$ The reaction leads to ketones $\mathbf{2} \mathbf{a}-\mathbf{b}$ with small amounts of dimers $\mathbf{4} \mathbf{a}-\mathbf{b}$ formed from deprotonation by the Grignard reagent followed by condensation on the cyano group..$^{13,14,18}$ With a monosubstituted $\alpha$-carbon, the substitution often is the major pathway, ${ }^{13-17,20-24}$ however, the addition was reported to be predominant in some cases. ${ }^{16,21,22,25,26}$

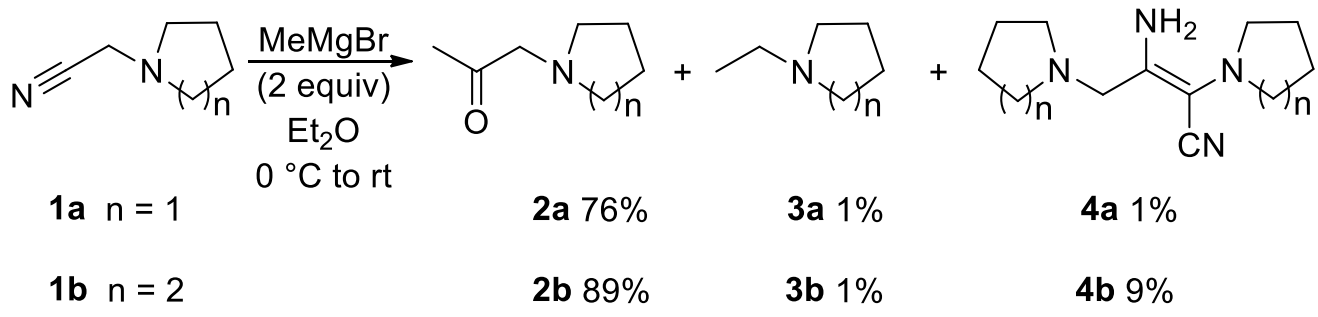

Scheme 2. Reactivity of $\alpha$-aminonitriles unsubstituted at the $\alpha$-carbon.

Hindered Grignard reagents also behave as hydride donors so that the decyanation reaction ${ }^{9,10}$ can become the major pathway. ${ }^{13,14,18,22,27,28}$ The reaction of $\alpha$-aminonitrile 5 with $n$-butylmagnesium chloride affords the substitution product $\mathbf{6 a}$ while the decyanation product $\mathbf{6 b}$ is the major product with tertbutylmagnesium chloride (Scheme 3 ). ${ }^{13}$ The formation of dimers from a possible radical pathway also was reported. ${ }^{11,13}$ Another side reaction is the formation of an enamine by deprotonation of the iminium ion, namely an overall and thus elimination of $\mathrm{HCN} \cdot{ }^{14,18,29-31}$ Starting from $\mathrm{N}$-monosubstituted substrates, the substitution is observed even for $\alpha$-aminonitriles unsubstituted at the $\alpha$-carbon. ${ }^{25,32}$

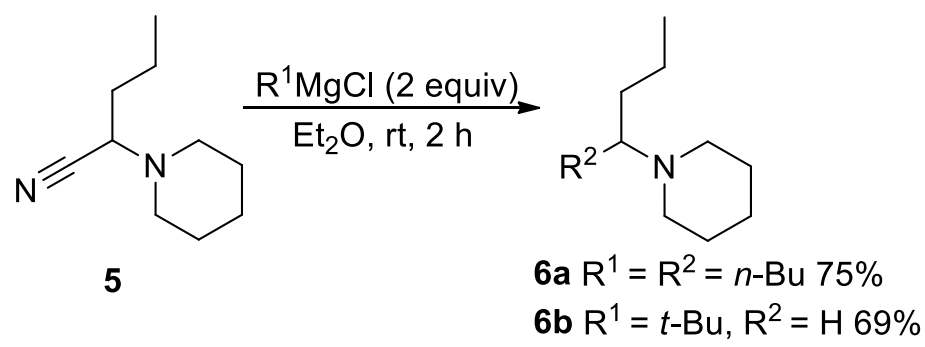

Scheme 3. Reductive decyanation of $\alpha$-aminonitrile 5 .

\section{Mechanism Considerations and Iminium Ion Promoters}

As shown in Scheme 1, the accepted mechanism proceeds by the loss of the cyanide ion followed by addition of the nucleophile on the resulting iminium ion. Starting from the reaction of a Grignard reagent with a combined aminonitrile-oxazolidine system, Aitken et al. consider the possible participation of another mechanism. This pathway, plausible according to orbital interactions, ${ }^{19}$ implies the formation of a N-Mg complex followed by an intramolecular substitution followed thus with inversion of configuration at the reactive center (Scheme 4$){ }^{33}$ 


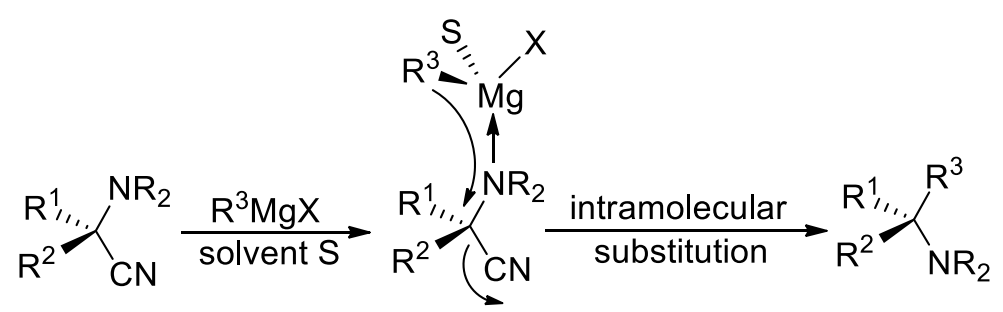

Scheme 4. Intramolecular substitution mechanism.

In this context, they examined the reaction of the chiral $\alpha$-aminonitrile 7. An iminium ion intermediate should lead to a racemic mixture while an inversion of configuration is expected with the path described in Scheme 4. Results obtained with 7 are shown in Table 1. The reaction proceeds with excellent yields with two equivalents of Grignard reagent but unreacted starting material was found with one equivalent. Interestingly, unreacted 7 was racemized while a racemic form of products was formed in agreement with the iminium ion intermediate formation. With one equivalent of $\mathrm{MeMgBr}$, the reaction appears very slow past $50 \%$ conversion and even after $43 \mathrm{~h}$, the reaction was not complete $(8 / 7=77 / 23)$. When $\mathrm{MeMgBr}$ was replaced by $\mathrm{MgBr}_{2} \cdot \mathrm{OEt}_{2}$, the reaction naturally did not take place but the starting aminonitrile was extensively racemized. ${ }^{33}$ Similar results are obtained when the phenyl group in $\mathbf{7}$ was replaced with a benzyl group.

Table 1. Bruylants reactions of enantiomerically enriched 7
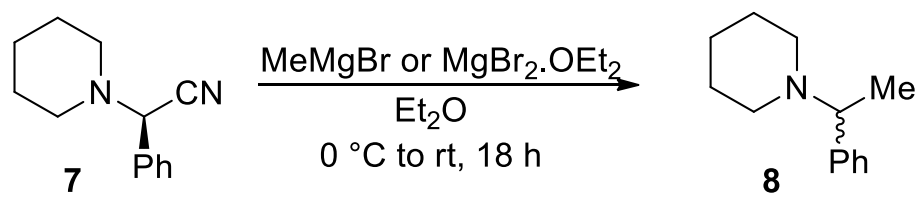

\begin{tabular}{cccc}
\hline 7, er & Conditions & Recovered 7, yield (\%), er & Product 8, yield (\%), er \\
\hline 92/8 & MeMgBr, 2 equiv & 0 & $97,50 / 50$ \\
$92 / 8$ & MeMgBr, 1 equiv & $45,50 / 50$ & $44,50 / 50$ \\
$77 / 23$ & $\mathrm{MgBr}_{2} \cdot \mathrm{OEt}_{2,}$ 2 equiv & $100,55 / 45$ & 0 \\
\hline
\end{tabular}

The authors then proposed a more detailed mechanism described in Scheme 5. One equivalent of the Grignard reagent helps to generate the iminium ion (step a) while the second equivalent adds to the iminium ion (b). The partial racemization of the unreacted $\alpha$-aminonitrile suggests that step (a) is equilibrated (c). $\mathrm{MgX}_{2}$ present in the medium as by-product or from the Schlenk equilibrium (e) could play a role in a concomitant cyanide elimination-readdition (d), while $\left(R^{3}\right)_{2} \mathrm{Mg}$ might act as nucleophile in step (b). ${ }^{14}$ 


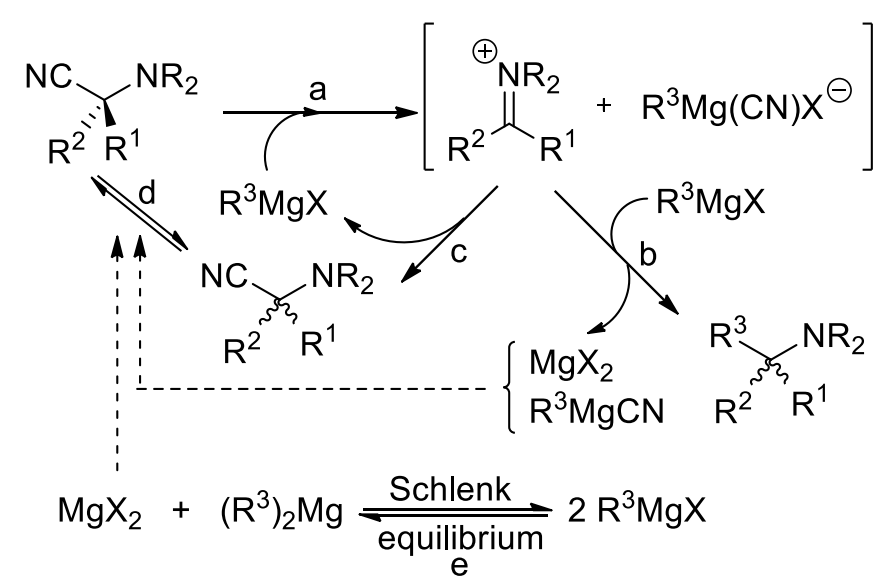

Scheme 5. Detailed mechanism proposed for the Bruylants reaction.

Although the use of 1.1 equivalents was reported, usually at least two equivalents of Grignard reagent are used in the Bruylants reaction. ${ }^{34}$ However, decyanating reagents are helpful to promote the loss of the cyanide ion and produce the iminium intermediate prior to the addition of the nucleophile. Silver salts, typically $\mathrm{AgBF}_{4}{ }^{29}$ and AgOTf have been used successfully. ${ }^{35}$ This effect was quantified by Agami and co-workers during the preparation of allylic amines. ${ }^{30}$ In this work, the $\alpha$-aminonitriles were treated with $\mathrm{AgBF}_{4}$ in $\mathrm{THF}_{\text {for }} 10$ minutes at room temperature prior to the addition of the vinylic Grignard reagent at low temperature. Selected results obtained with vinylmagnesium bromides are reported in Scheme 6 . Curiously, with acetylenic Grignard reagents, the addition of $\mathrm{AgBF}_{4}$ was less efficient or even counterproductive. When $\alpha$-aminonitriles 9 or $\mathbf{1 0}$ precursors of tertiary amines $\mathbf{1 1}$ were treated with $\mathrm{AgBF}_{4}$ in $\mathrm{CDCl}_{3}$, signals typical of the iminium ions where observed by NMR. ${ }^{36}$

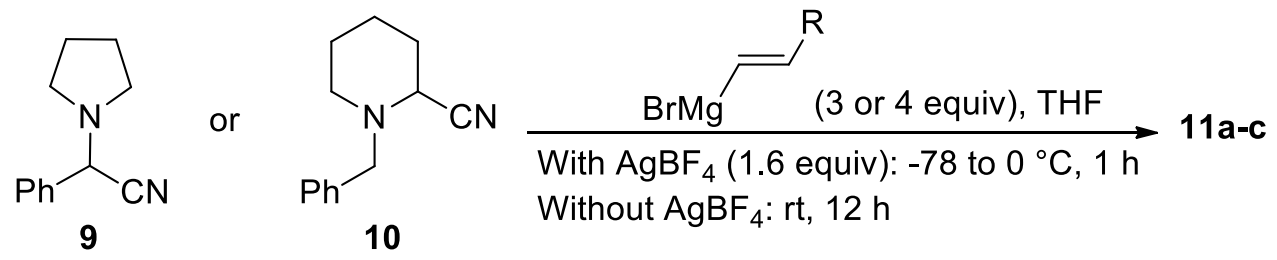<smiles>C=CC(c1ccccc1)N1CCCC1</smiles><smiles>C(/C=C/c1ccccc1)=C\c1ccccc1</smiles><smiles>C=CC1CCCCN1Cc1ccccc1</smiles>

11a $98 \%(32 \%)$

$11 \mathrm{~b} 60 \%$ (traces) 11c $91 \%(30 \%)$

Scheme 6. Effect of $\mathrm{AgBF}_{4}$ as additive. Yields in brackets refer to yields without $\mathrm{AgBF}_{4}$.

\section{Synthetic Applications}

\subsection{Enantioselective synthesis of clavepictine analogues}

Agami and co-workers prepared a series of clavepictine analogues and tested their cytotoxic activity. For this work end, they synthetized $\alpha$-aminonitrile 12 which was reacted with various Grignard reagents (Scheme 7). ${ }^{37}$ 
Substitution products 13 are obtained with good yields and high stereocontrol. The stereoselectivity can be explained by an axial attack on the iminium ion conformer 14 in a chair-like transition state. The analogy with the stereoelectronic principles developed by Steven ${ }^{38}$ allows the rationalization of stereoselectivities observed in Bruylants reactions involving tetrahydropyridinium type intermediates. ${ }^{29,39-43}$

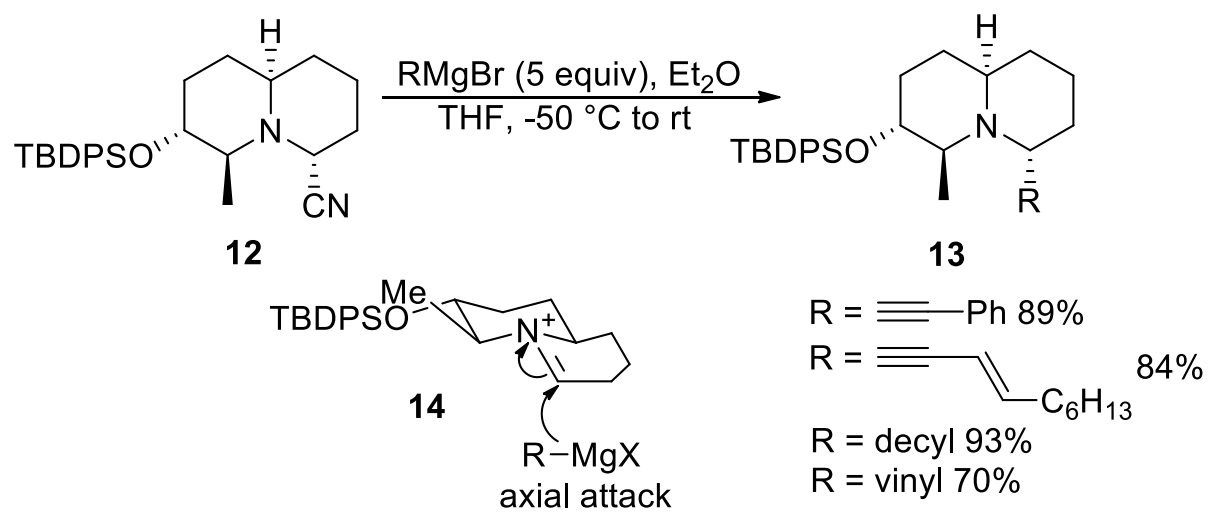

Scheme 7. Synthesis of precursors of clavepictine analogues. When $\mathrm{R}=$ vinyl, 12 was first treated with 1.5 equiv of $\mathrm{AgBF}_{4}$ at room temperature for 10 minutes, then vinylmagnesium bromide in THF was added at -78 ${ }^{\circ} \mathrm{C}$. TBDPS = tert-butyldiphenylsilyl.

\subsection{Dual reactivity of $\alpha$-aminonitriles: Bruylants versus alkylation-decyanation reactions}

Two pathways for the substitution of the cyano group are possible (Scheme 8). ${ }^{24}$ The Bruylants reaction (path a) or deprotonation, alkylation and reductive decyanation by hydride donors (path b). ${ }^{44,45}$ Both sequences go through an iminium ion. When a facial discrimination of this intermediate is possible, the configuration of the new chiral center can be induced and a diastereoselectivity is obtained. This dual reactivity was used during the preparation of $(+)$ - and (-)-coniine ${ }^{29}$ or indolizidine alkaloids. ${ }^{40,42,43}$ Alternatively, the decyanation step can take place by using dissolving metal conditions. ${ }^{46}$
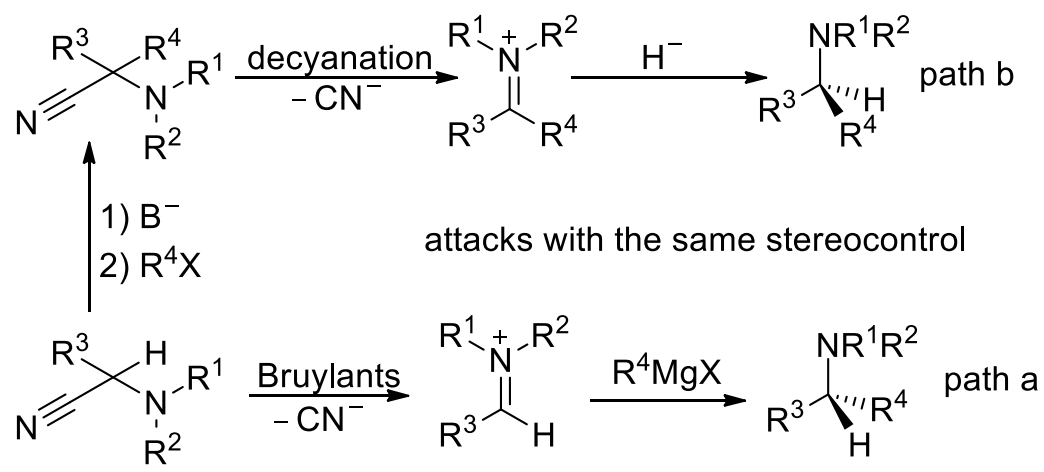

Scheme 8. Substitution pathways for $\alpha$-aminonitriles.

Hyacinthacines belong to the class of pyrrolizidine alkaloids, ${ }^{47-49}$ and some representatives have been prepared using a Bruylants reaction. ${ }^{35,50,51}$ Delair and co-workers obtained the two epimers hyacinthacines $A_{6}$ and $A_{7} .{ }^{52}$ In their strategy, they envisioned that a bulk protecting group of the cis-hydroxyl groups could play an important role in the steric differentiation of the two reagent faces and introduced a benzylidene diol protection. For the preparation of hyacinthacine $A_{6}, \alpha$-deprotonation of protected diol 15 followed by 
alkylation afforded the methylated aminonitrile 16. Reductive decyanation using $\mathrm{LiEt}_{3} \mathrm{BH}$ (Super-Hydride ${ }^{\circledR}$ ) gave the desired isomer 17 precursor of hyacinthacine $A_{6}$ (Scheme 9).

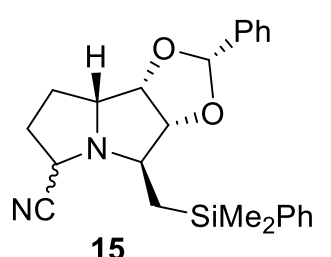

15
1) LDA, THF

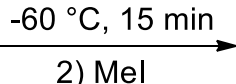

$-60{ }^{\circ} \mathrm{C}, 30 \mathrm{~min}$

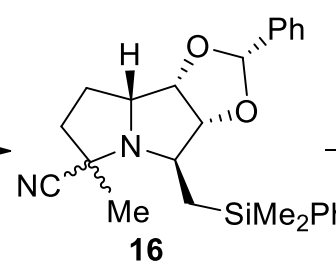

16

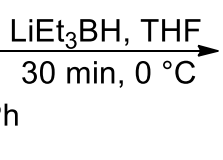

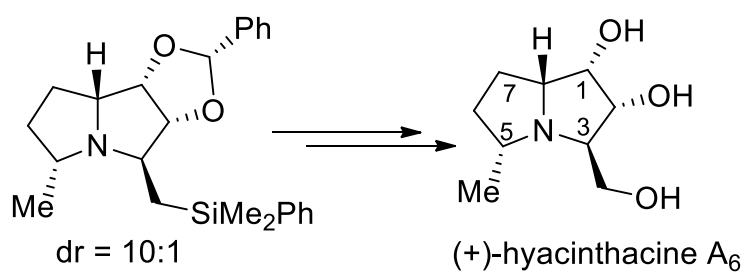

(+)-hyacinthacine $A_{6}$

$1778 \%$ (major isomer, 2 steps)

Scheme 9. Synthesis of hyacinthacine $A_{6}$.

The authors then projected to obtain the hyacinthacine $A_{7}$, the $C-5$ epimer, by using a Bruylants reaction. Unfortunately, when the Bruylants reaction with $\mathrm{MeMgBr}$ was performed on $\alpha$-aminonitrile 15 , the preferred attack on the less hindered exo face occurred only with a poor stereoselectivity $(\mathbf{1 7}, \mathrm{dr} \leq 3: 2)$. Further investigations led the authors to reduce steric hindrance at the C-3 position and to use a bulkier Grignard reagent. They chose the dimethylphenylsilylmethyl group as a methyl equivalent and introduced a benzyloxymethyl group at C-3 (18). The Bruylants reaction starting from $\mathrm{PhMe}_{2} \mathrm{SiCH}_{2} \mathrm{MgBr}$ and 18 afforded 19, precursor of hyacinthacine $A_{7}$, with high diastereoselectivity (Scheme 10).
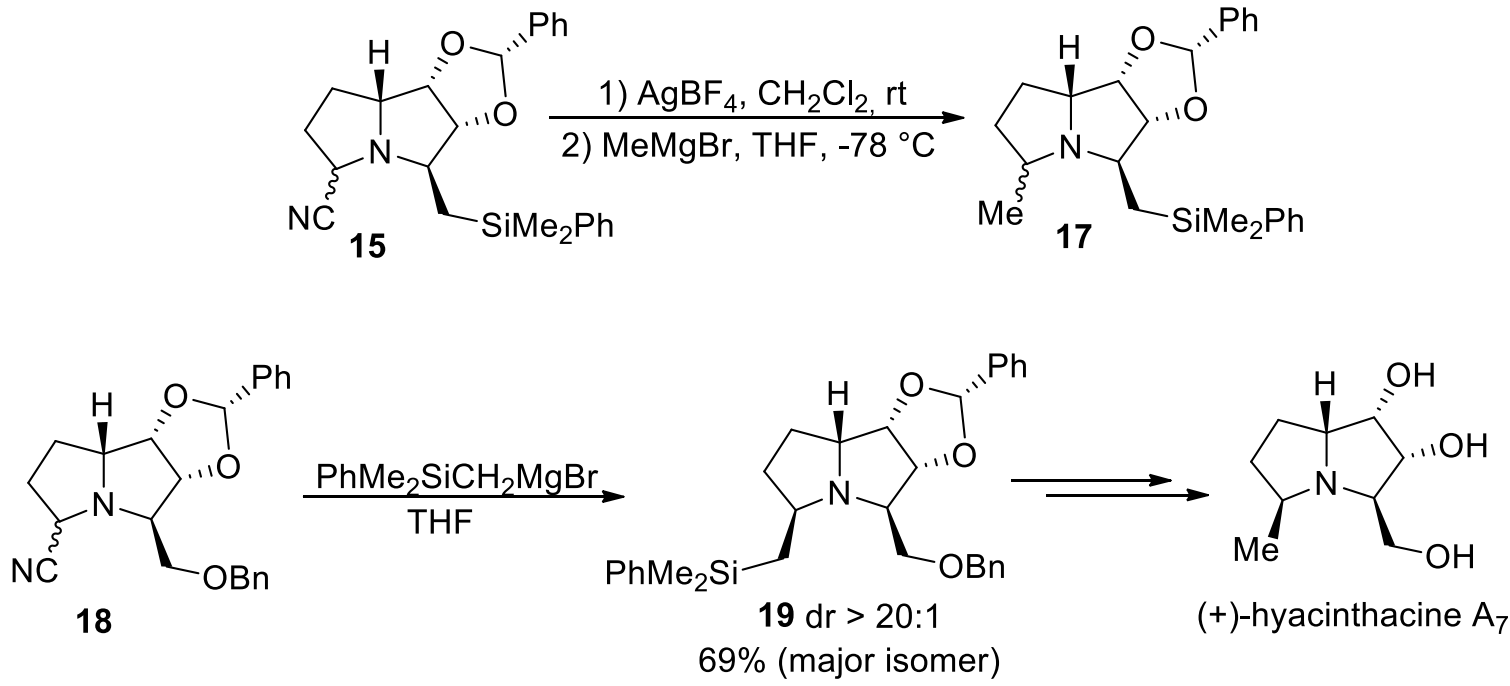

Scheme 10. Synthesis of hyacinthacine $A_{7} . B n=$ benzyl.

\subsection{Strecker-Bruylants sequence. Intramolecular Bruylants reactions}

In 1850, Strecker described a synthesis of $\alpha$-aminonitriles starting from acetaldehyde, ammonia and hydrogen cyanide. Today this synthesis remains highly popular so that variants, improvements as well as asymmetric versions are still emerging. ${ }^{2,53-55}$ The Strecker-Bruylants sequence is a common way in organic synthesis. ${ }^{56-64}$ Thoma and co-workers discovered NIBR-1282, an orally bioavailable CCR5-antagonist active in vivo. ${ }^{65}$ Starting from amine 20, the Strecker reaction was Ti(IV)-catalyzed and used $\mathrm{Et}_{2} \mathrm{AICN}$ as cyanide source. Treatment of $\alpha$ aminonitrile $\mathbf{2 1}$ with an excess of Grignard reagent afforded intermediate 22 precursor of NIBR-1282 (Scheme 11). 


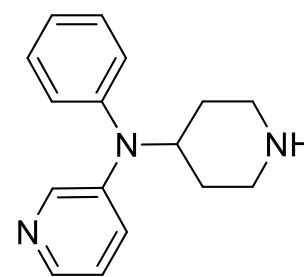

20
1)

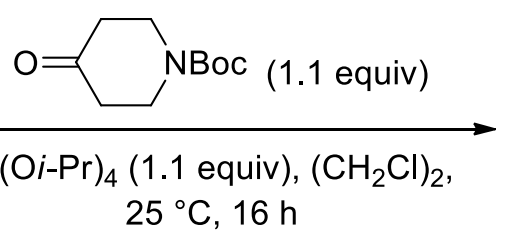

2) $\mathrm{Et}_{2} \mathrm{AICN}$ (2.2 equiv), toluene $25^{\circ} \mathrm{C}, 4 \mathrm{~h}$

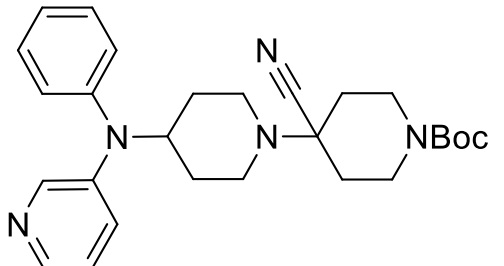

$2177 \%$

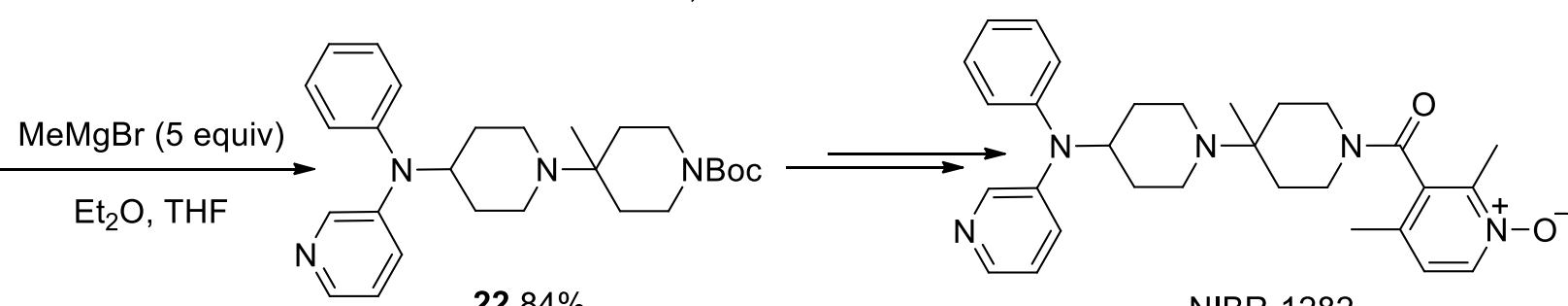

$2284 \%$

NIBR-1282

Scheme 11. Synthesis of NIBR-1282 using a Strecker-Bruylants sequence. Boc = tert-butoxycarbonyl.

Intramolecular Strecker and Bruylants reactions also have been applied. ${ }^{66,67}$ The last two steps of the synthesis of cis-erythrinane, both intramolecular, are depicted in Scheme $12 .{ }^{68}$ The intermediate 23, containing both secondary amine and a protected carbonyl group is first hydrolyzed and treated with KCN to give 24. Curiously, generating the organomagnesium from 24 with $\mathrm{Mg}$ lead to a complex reaction mixture. Thus, the Grignard reagent was cleanly prepared by a halogen-magnesium exchange reaction using $i$ propylmagnesium chloride at $-50{ }^{\circ} \mathrm{C}$ while the Bruylants reaction required an elevation of temperature. The authors used a similar strategy for the synthesis of 1-benzyl-1,2,3,4-tetrahydroisoquinolines. ${ }^{66}$

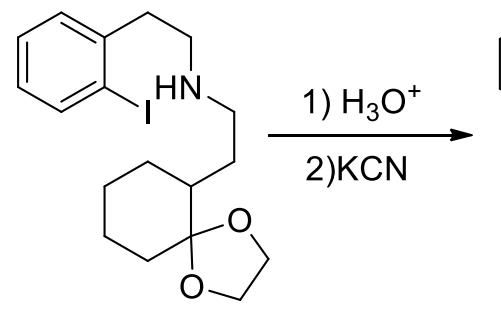

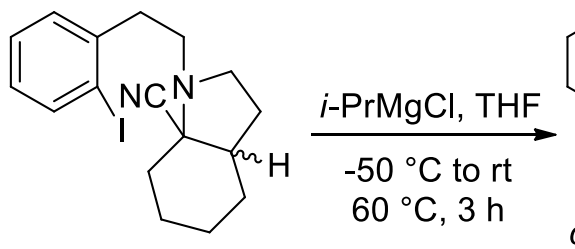

$2497 \%$

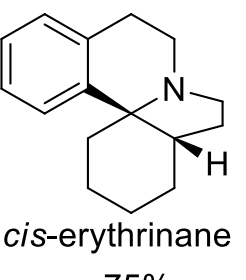

$75 \%$

23

Scheme 12. Intramolecular Bruylants reaction.

\section{Reactions of $\alpha$-Aminonitriles with other Organometallic Reagents}

Starting from $N, N$-disubstituted $\alpha$-aminonitriles, the more reactive organolithium reagents show a marked tendency towards nucleophilic addition ${ }^{14,22,25,31,64,67,69,70}$ even if the substitution has been observed with poor yields. ${ }^{71}$ However, $\mathrm{N}$-monosubstituted substrates reveal a preference for the substitution pathway, via the formation of a Schiff base. ${ }^{25,32}$ Kudzma and co-workers have prepared 4-heteroaryl-4-anilinopiperidines by a modified Bruylants reaction (Scheme 13). ${ }^{72}$ The starting nitriles 25 (1 equiv) were added to a lithiated thiazole derivative ( 2 equiv). Elimination of hydrogen cyanide leads to the Schiff base $\mathbf{2 6}$ which is attacked by the second equivalent of the lithiated heterocycle to give the final product in high yields (27a-c). The reaction also 
was successful from 2-lithio-5-methylfuran (27d) and 2-lithiopyridine (27e) but a modest yield was obtained with 2-lithiothiophene (27f).

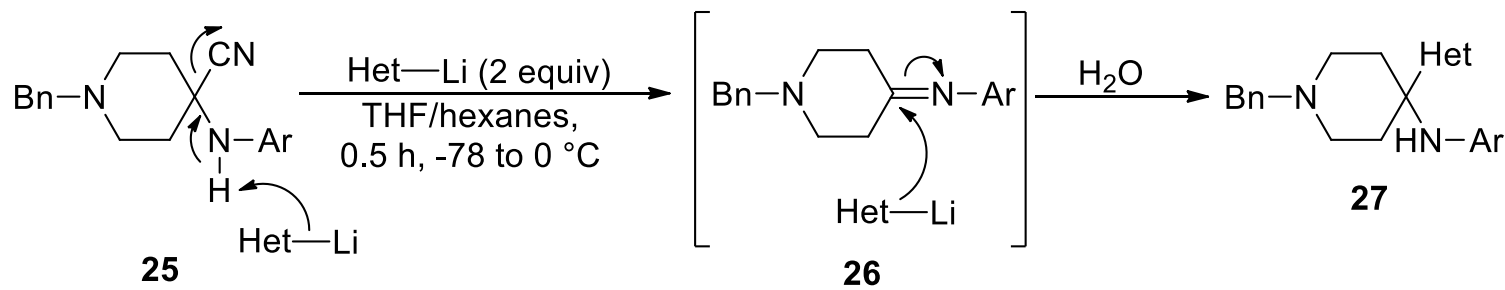

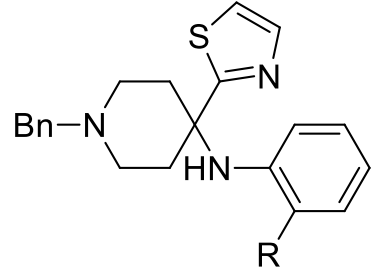

27 a $89 \%$ and $92 \%$

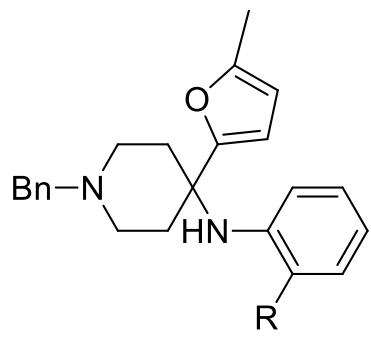

27d $R=F, 57 \%$

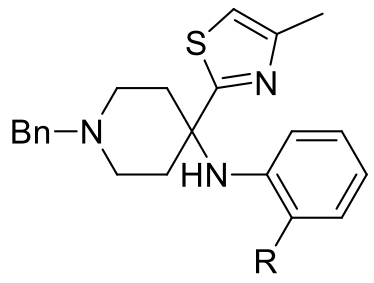

27b $87 \%$ and $98 \%$

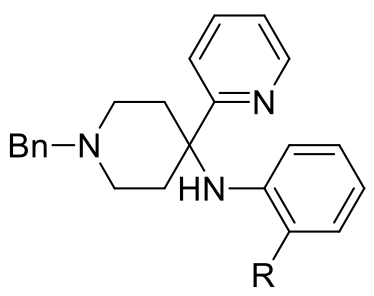

27e $51 \%$ and $71 \%$

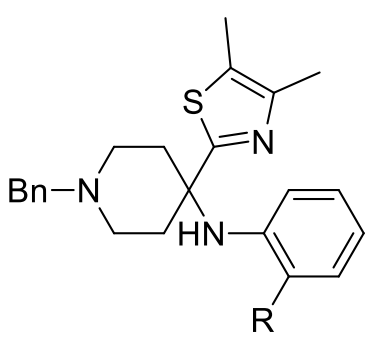

27c $87 \%$ and $85 \%$

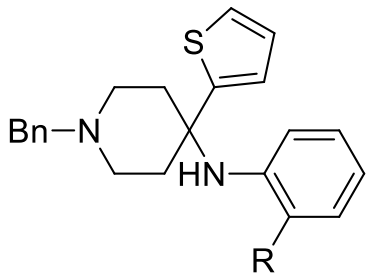

$27 f R=F, 20 \%$

Scheme 13. Synthesis of 4-heteroaryl-4-anilinopiperidines from lithiated heterocycles. Yields refer successively to $\mathrm{R}=\mathrm{H}$ and $\mathrm{R}=\mathrm{F}$ except in the case of $\mathbf{2 7} \mathbf{d}$ and $\mathbf{2 7 f}$.

Allyl and propargyl zinc halides are quite good nucleophiles and appear as fair substitutes in the Bruylants reaction. ${ }^{73-75}$ Bernardi et al. performed the Bruylants reaction under Barbier and Reformatsky conditions and thus generated the organometallic species in situ. ${ }^{76}$ In this work, $\alpha$-aminonitriles were prepared by the Suginome's procedure, from aldehydes and bis(dialkylamino)cyanoboranes. ${ }^{77}$ In the standard procedure, allyl bromide or ethyl bromoacetate, zinc and acetic acid were successively added to a solution of $\alpha$-aminonitriles in THF. Addition of the acetic acid was determinant and could be related to the activation of the metal surface or the generation of the iminium ion. Examples are given in Scheme 14. Homoallylamines $\mathbf{2 8}$ or $\beta$-aminoesters 29 are formed, generally in good yields, respectively from the Barbier and Reformatsky conditions. While steric hindrance does not seem to affect the Reformatsky reaction, this is not the case under Barbier conditions. When reactions are sluggish at room temperature, heating to reflux after addition of acetic acid appears beneficial (28d-e) (Scheme 14). 


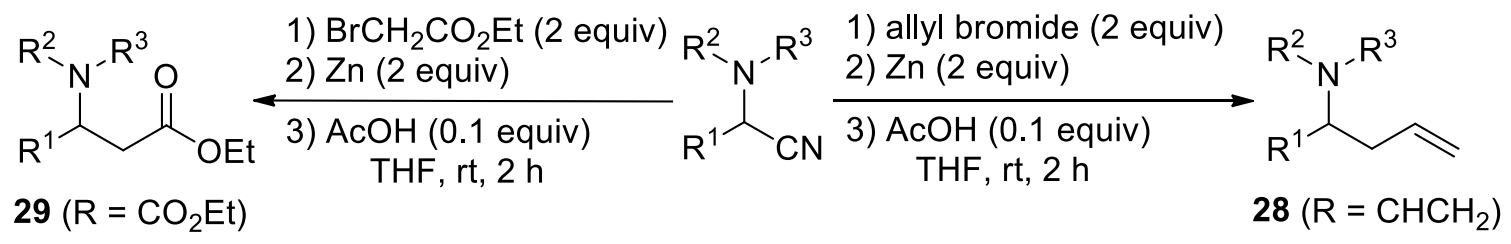<smiles>[R]CC(c1ccccc1)N1CCCC1</smiles>

28a $65 \%$ 29a $75 \%$<smiles>[R]CC([Ge])N1CCOCC1</smiles>

28d, traces or $66 \%$ (reflux for $2 \mathrm{~min}$ ) 29d $80 \%$<smiles>[R]CC(C1CCCC1)N1CCCC1</smiles>

28b $82 \%$

29b $45 \%$<smiles>[R]CC(C1CCCCC1)N(Cc1ccccc1)Cc1ccccc1</smiles>

28e $15 \%$ or $38 \%$ (reflux for $2 \mathrm{~min}$ ) 29 e $87 \%$<smiles>[R]CC(CCc1ccccc1)N1CCCC1</smiles>

28c $75 \%$ 29c $50 \%$<smiles>[R]CC(C1CCCCC1)N(CC=C)Cc1ccc(OC)cc1</smiles>

28f $72 \%$ 29f $84 \%$

Scheme 14. Reaction of organozincs under Barbier and Reformatsky conditions. Cy = cyclohexyl.

Poor nucleophiles such as alkyl and aryl zinc reagents have been used successfully. ${ }^{78}$ Martin and coworkers prepared libraries of 1,2,3-triazole-fused 1,4-benzodiazepines, privileged substructures for drug discovery. They exploited the $\alpha$-aminonitrile functionality to introduce diversification in their structures. ${ }^{79,80}$ Besides the Reformatsky reaction, they also used methyl and phenylzinc bromides. The authors first observed the $\alpha$-deprotonation to the cyano group when they treated $\alpha$-aminonitrile $30 f\left(R^{1}=4-O_{M} C_{6} H_{4}\right) w_{i t h}$ phenylmagnesium bromide. After quenching the reaction mixture with acetic acid- $d_{4}$, they obtained $31 \mathbf{f}$ in $56 \%$ yield accompanied with starting material 30f recovery containing more than $95 \%$ deuterium incorporation. To avoid the competitive deprotonation and to increase yields, weakly basic organozincs were first generated in situ by transmetallation with $\mathrm{ZnCl}_{2}$ of the Grignard reagents, the $\alpha$-aminonitriles $\mathbf{3 0}$ then were added (Scheme 15). 
<smiles>[R1]CN1Cc2cnnn2-c2ccccc2C1C#N</smiles><smiles>CC1c2ccccc2-n2nncc2CN1C</smiles>

31a $73 \%$<smiles>c1ccc(C2c3ccccc3-n3nncc3CN2CC2CCCCC2)cc1</smiles>

31d $73 \%$<smiles>CN1Cc2cnnn2-c2ccccc2C1c1ccccc1</smiles>

31b $86 \%$<smiles>CC1c2ccccc2-n2nncc2CN1CC1CCCCC1</smiles>

31c $75 \%$

Scheme 15. Reaction of organozincs generated through transmetallation.

\section{Alternatives to $\alpha$-Aminonitriles}

When the cyanide source is replaced by a heterocyclic nucleophile, a safer route is available and side reactions due to the nucleophilic attack on the nitrile are avoided. In the course of studies on benzotriazoles mediated aminoalkylations, ${ }^{81}$ Katritzky and co-workers proposed the preparation of new benzotriazolyl adducts by mixing cyclic ketones with benzotriazole and primary or secondary amines. ${ }^{82}$ Scheme 16 shows this sequence starting from cyclohexanone and morpholine. The adduct 32 reacts with Grignard reagents to yield the substitution products $\mathbf{3 4}$ or $\mathbf{3 5}$. Good yields are usually obtained but replacing benzotriazole with pyrazole afforded slightly lower yields. Reactions of vinyl and alkynyl Grignard reagents with 1-( $\alpha$ aminoalkyl)benzotriazoles also produced the desired amines. ${ }^{83}$

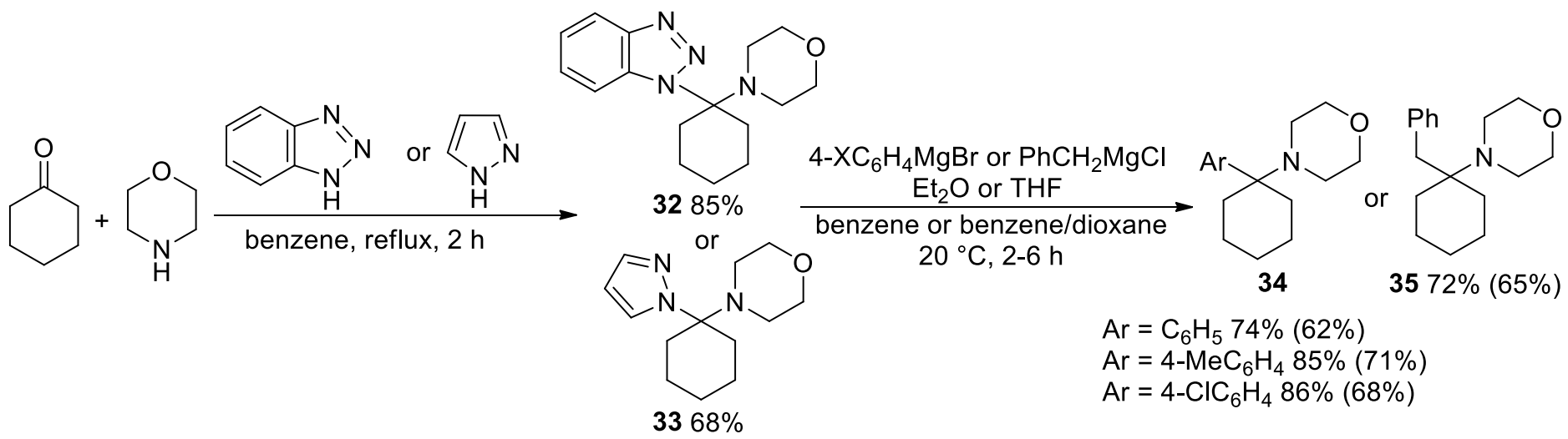

Scheme 16. Preparation of tertiary amines from benzotriazole or pyrazole adducts and Grignard reagents. Yields in brackets refer to yields from 33. 
This methodology was extended to the less reactive hindered ketones. Adducts $\mathbf{3 6}$ were first prepared from the reaction between the enamines corresponding to ketones and benzotriazole $(\mathrm{BtH}) .{ }^{84} \mathrm{In}$ situ treatment with various nucleophiles affords products usually in fair to good yields (Scheme 17). ${ }^{85}$ The reaction with Grignard reagents affords tertiary alkyl amines (37a-d), treatment with lithium phenylacetylide yields propargylamines (38a-d) while lithiated heterocycles give $\alpha$-heteroarylamines (39a-d).

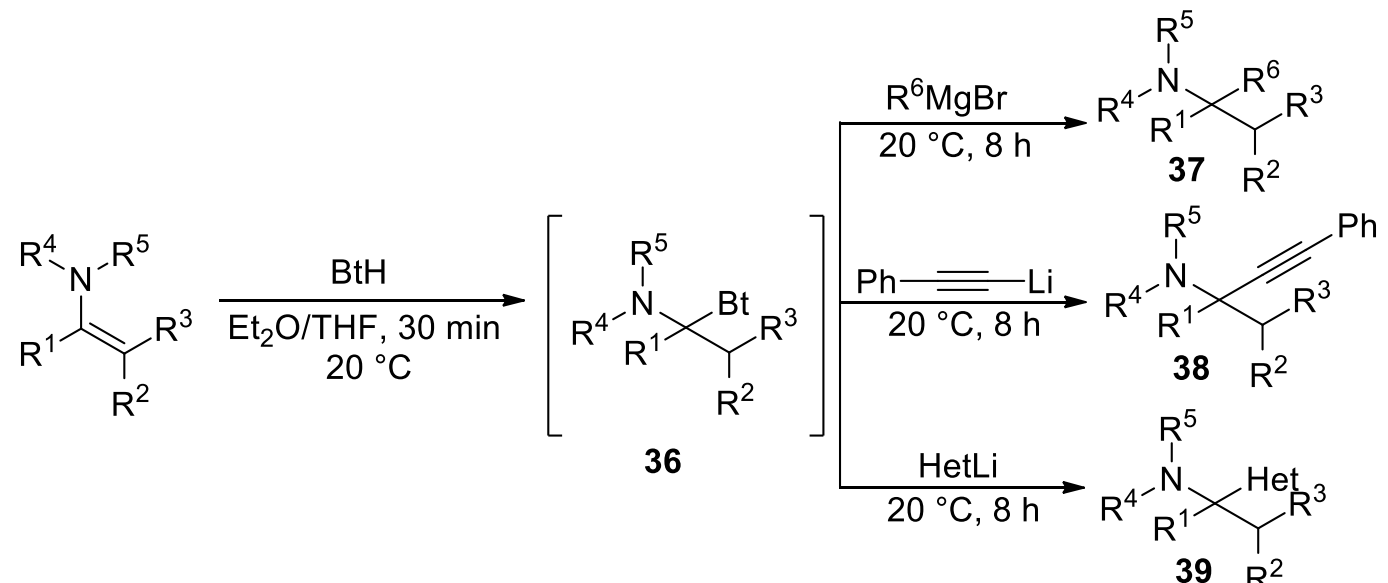

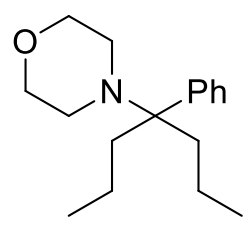

37 a $61 \%$<smiles>C(#CC1(N2CCOCC2)CCCCC1)c1ccccc1</smiles>

38a $98 \%$

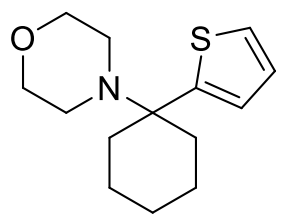

39 a $85 \%$<smiles>CCC(Br)(CC)N1CCOCC1</smiles>

$37 \mathrm{~b} 60 \%$

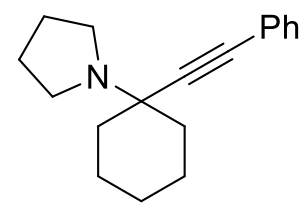

38b $67 \%$

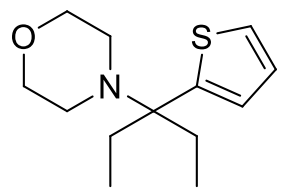

39b $73 \%$<smiles>C=CC(CCC)(CCC)N1CCOCC1</smiles>

37c $51 \%$

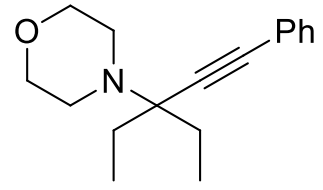

38c $92 \%$

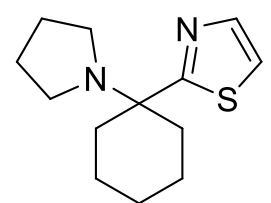

39c $54 \%$

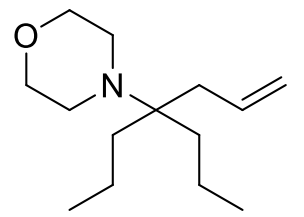

37d 56\%

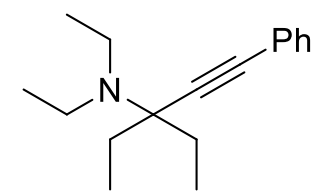

38d 30\%

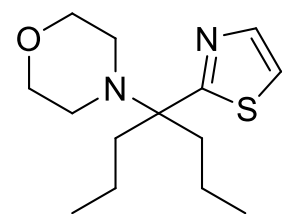

39d $80 \%$

Scheme 17. Preparation of tertiary amines from benzotriazole adducts and Grignard or organolithium reagents.

Prashad and co-workers compared benzotriazole, 1,2,3- and 1,2,4-triazoles and found that 1,2,3-triazole gave the best yields (Scheme 18). ${ }^{86}$ Ketones and secondary amines were heated in toluene at $108-114{ }^{\circ} \mathrm{C}$ with a triazole derivative. The resulting adduct $\mathbf{4 0}$ was not isolated and added to a solution of the Grignard reagent in THF, after reaction high yields are obtained (41a-d). Starting from cycloheptanone or cyclopentanone, the substitution products were obtained in lower yields (41e-f), however the use of 1,2,3-triazole was still beneficial (41e). Routes described in Schemes 17-18 were used in the synthesis of novel analogues of phencyclidine. ${ }^{64,87,88}$ 


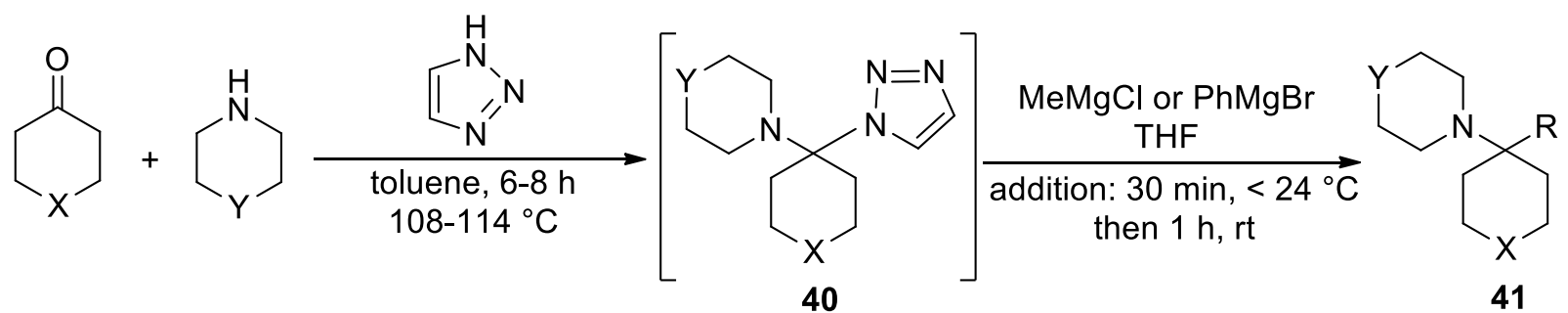<smiles>c1ccc(C2(N3CCCCC3)CCCCC2)cc1</smiles>

41a $80 \%$

$54 \%$ (1,2,4-triazole)

$55 \%$ (benzotriazole)<smiles>CC(C)(C)OC(=O)N1CCC(C)(N2CCOCC2)CC1</smiles>

41d $90 \%$<smiles>c1ccc(C2(N3CCOCC3)CCCCC2)cc1</smiles>

41b $84 \%$

$68 \%$ (1,2,4-triazole)

$67 \%$ (benzotriazole)<smiles>c1ccc(C2(N3CCOCC3)CCCCCC2)cc1</smiles>

41e $45 \%$ $13 \%$ (benzotriazole)<smiles>CN1CCN(C2(C)CCN(C(=O)OC(C)(C)C)CC2)CC1</smiles>

41c $79 \%$<smiles>CC1(N2CCOCC2)CCCC1</smiles>

41 f $38 \%$

Scheme 18. Preparation of tertiary amines from 1,2,3-triazole adducts. Yields from adducts derived from 1,2,4-triazole or benzotriazole also are given for 41a,b,e.
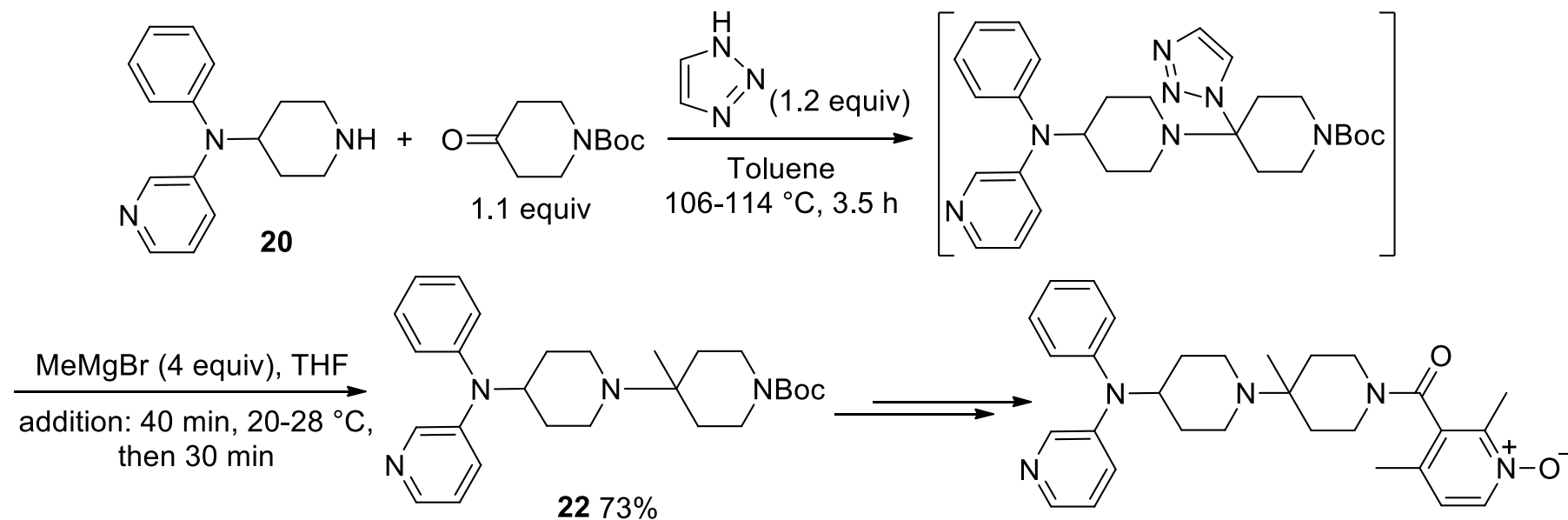

NIBR-1282

Scheme 19. Synthesis of NIBR-1282 using the 1,2,3-triazole route.

Later this group reinvestigated the synthesis of NIBR-1282 outlines in Scheme 11. They developed each step of this route into a scalable process with the aim to work on a kilogram scale. ${ }^{89}$ In particular, they used 1,2,3-triazole instead of the cyanide source, the Strecker and Bruylants reactions were replaced by the variant, in one step, described in Scheme 19. The yield increases from 65\% (2 steps, Scheme 11) to 73\%. Interestingly, the authors analyzed the reaction mixture for various heterocycle analogues before the reaction with the 
Grignard reagent. The less basic 1,2,3-triazole minimized the enamine formation (1\%, relative yield) compared to $1,2,4$-triazole $(9 \%)$ or pyrazole $(26 \%)$.

\section{Conclusions}

Since its discovery, almost one hundred years ago, the Bruylants reaction has been widely used in organic synthesis and usually proceeds with good yields and high levels of stereoselectivity. Various Grignard reagents are applicable and the reaction has been extended to organozinc as nucleophiles. Nitrogen heterocycles as leaving groups appear as a safer and practical alternative to the cyanide ion and allow the use of organolithiums as the attacking nucleophiles. The substitution of the cyano group also is achieved by $\alpha$ deprotonation-alkylation followed by a decyanation reaction. Switching from this sequence to the Bruylants reaction induces opposite stereoselectivities.

\section{References}

1. Shafran, Y. M.; Bakulev, V. A.; Mokrushin, V. S. Usp. Khim. 1989, 58, 250-274.

https://doi.org/10.1070/RC1989v058n02ABEH003432

2. Kouznetsov, V. V.; Puerto Galvis, C. E. Tetrahedron 2018, 74, 773-810.

https://doi.org/10.1016/j.tet.2018.01.005

3. Enders, D.; Shilvock, J. P. Chem. Soc. Rev. 2000, 29, 359-373.

https://doi.org/10.1039/a908290e

4. Husson, H.-P.; Royer, J. Chem. Soc. Rev. 1999, 28, 383-394.

https://doi.org/10.1039/a900153k

5. Otto, N.; Opatz, T. Chem. Eur. J. 2014, 20, 13064-13077.

https://doi.org/10.1002/chem.201403956

6. Josse, S.; Postel, D. Top. Heterocycl. Chem. 2019, 57, 137-169.

https://doi.org/10.1007/7081 201935

7. Grundke, C.; Vierengel, N.; Opatz, T. Chem. Rec. 2020, 20, 989-1016.

https://doi.org/10.1002/tcr.202000066

8. Opatz, T. Synthesis 2009, 1941-1959.

https://doi.org/10.1055/s-0029-1216839

9. Mattalia, J.-M.; Marchi-Delapierre, C.; Hazimeh, H.; Chanon, M. Arkivoc 2006, (iv), 90-118. https://doi.org/10.3998/ark.5550190.0007.408

10. Mattalia, J.-M. R. Beilstein J. Org. Chem. 2017, 13, 267-284.

https://doi.org/10.3762/bjoc. 13.30

11. Bruylants, P. Bull. Soc. Chim. Belg. 1924, 33, 467-478.

12. Bruylants, P. Bull. Cl. Sci., Acad. R. Belg. 1925, 11, 261-280.

13. Thies, H.; Schönenberger, H.; Qasba, P. K. Arch. Pharm. 1969, 302, 30-42. https://doi.org/10.1002/ardp.19693020106

14. Chauvière, G.; Tchoubar, B.; Welvart, Z. Bull. Soc. Chim. Fr. 1963, 1428-1433.

15. Stevens, T. S.; Cowan, J. M.; MacKinnon, J. J. Chem. Soc. 1931, 2568-2572.

https://doi.org/10.1039/JR9310002568 
16. Thomson, T.; Stevens, T. S. J. Chem. Soc. 1932, 2607-2612. https://doi.org/10.1039//ir9320002607

17. Welvart, Z. Compt. Rend. 1960, 250, 1870-1872.

18. Sansoulet, J.; Tackx, C.; Welvart, Z. Compt. Rend. 1960, 250, 4370-4372.

19. Aitken, D. J.; Beaufort, V.; Chalard, P.; Cladière, J.-L.; Dufour, M.; Pereira, E.; Théry, V. Tetrahedron 2002, 58, 5933-5940.

https://doi.org/10.1016/S0040-4020(02)00501-X

20. Christiaen, A. Bull. Soc. Chim. Belg. 1924, 33, 483-490.

21. Goodson, L. H.; Christopher, H. J. Am. Chem. Soc. 1950, 72, 358-362.

https://doi.org/10.1021/ja01157a097

22. Morris, G. F.; Hauser, C. R. J. Org. Chem. 1962, 27, 465-471.

https://doi.org/10.1021/j001049a030

23. Brown, H. C.; Zaidlewicz, M.; Dalvi, P. V.; Narasimhan, S.; Mukhopadhyay, A. Organometallics 1999, 18, 1305-1309.

https://doi.org/10.1021/om9806287

24. Orejarena Pacheco, J. C.; Lipp, A.; Nauth, A. M.; Acke, F.; Dietz, J.-P.; Opatz, T. Chem. Eur. J. 2016, 22, 5409-5415.

https://doi.org/10.1002/chem.201504845

25. Yoshimura, J.; Ohgo, Y.; Sato, T. Bull. Chem. Soc. Jpn. 1965, 38, 1809-1813.

https://doi.org/10.1246/bcsj.38.1809

26. Leclerc, E.; Vrancken, E.; Mangeney, P. J. Org. Chem. 2002, 67, 8928-8937. https://doi.org/10.1021/jo025872t

27. Chauvière, G.; Vetter, W.; Welvart, Z. Compt. Rend. 1964, 258, 4287-4289.

28. Taylor, H. M.; Hauser, C. R. J. Am. Chem. Soc. 1960, 82, 1960-1965. https://doi.org/10.1021/ja01493a031

29. Guerrier, L.; Royer, J.; Grierson, D. S.; Husson, H.-P. J. Am. Chem. Soc. 1983, 105, 7754-7755. https://doi.org/10.1021/ja00364a053

30. Agami, C.; Couty, F.; Evano, G. Org. Lett. 2000, 2, 2085-2088.

https://doi.org/10.1021/ol0059908

31. Zhu, J.; Quirion, J.-C.; Husson, H.-P. J. Org. Chem. 1993, 58, 6451-6456. https://doi.org/10.1021/jo00075a048

32. Overman, L. E.; Burk, R. M. Tetrahedron Lett. 1984, 25, 1635-1638.

https://doi.org/10.1016/S0040-4039(01)81131-X

33. Beaufort-Droal, V.; Pereira, E.; Théry, V.; Aitken, D. J. Tetrahedron 2006, 62, 11948-11954. https://doi.org/10.1016/j.tet.2006.09.087

34. Ahlbrecht, H.; Dollinger, H. Synthesis 1985, 743-748. https://doi.org/10.1055/s-1985-31330

35. Hu, X.-G.; Jia, Y.-M.; Xiang, J.; Yu, C.-Y. Synlett 2010, 982-986. https://doi.org/10.1055/s-0029-1219540

36. Hu, X.-G.; Ariawan, A. D.; Hunter, L. Tetrahedron Lett. 2014, 55, 7222-7225. https://doi.org/10.1016/i.tetlet.2014.11.024

37. Agami, C.; Couty, F.; Evano, G.; Darro, F.; Kiss, R. Eur. J. Org. Chem. 2003, 2062-2070. https://doi.org/10.1002/ejoc.200300057

38. Stevens, R. V. Acc. Chem. Res. 1984, 17, 289-296. 
https://doi.org/10.1021/ar00104a005

39. Amorde, S. M.; Jewett, I. T.; Martin, S. F. Tetrahedron 2009, 65, 3222-3231.

https://doi.org/10.1016/j.tet.2008.10.074

40. Enders, D.; Thiebes, C. Synlett 2000, 1745-1748.

https://doi.org/10.1055/s-2000-8675

41. Sun, P.; Sun, C.; Weinreb, S. M. J. Org. Chem. 2002, 67, 4337-4345.

https://doi.org/10.1021/j00201070

42. Polniaszek, R. P.; Belmont, S. E. J. Org. Chem. 1990, 55, 4688-4693.

https://doi.org/10.1021/j000302a038

43. Polniaszek, R. P.; Belmont, S. E. J. Org. Chem. 1991, 56, 4868-4874.

https://doi.org/10.1021/jo00016a013

44. Lipp, A.; Ferenc, D.; Gütz, C.; Geffe, M.; Vierengel, N.; Schollmeyer, D.; Schäfer, H. J.; Waldvogel, S. R.;

Opatz, T. Angew. Chem., Int. Ed. 2018, 57, 11055-11059.

https://doi.org/10.1002/anie.201803887

45. Otto, N.; Ferenc, D.; Opatz, T. J. Org. Chem. 2017, 82, 1205-1217.

https://doi.org/10.1021/acs.joc.6b02647

46. Yue, C.; Gauthier, I.; Royer, J.; Husson, H.-P. J. Org. Chem. 1996, 61, 4949-4954.

https://doi.org/10.1021/j0960398a

47. Desvergnes, V.; Landais, Y. Stud. Nat. Prod. Chem. 2014, 42, 373-419.

https://doi.org/10.1016/B978-0-444-63281-4.00013-6

48. Robertson, J.; Stevens, K. Nat. Prod. Rep. 2014, 31, 1721-1788.

https://doi.org/10.1039/C4NP00055B

49. Robertson, J.; Stevens, K. Nat. Prod. Rep. 2017, 34, 62-89.

https://doi.org/10.1039/C5NP00076A

50. Reddy, P. V.; Koos, P.; Veyron, A.; Greene, A. E.; Delair, P. Synlett 2009, 1141-1143.

https://doi.org/10.1055/s-0028-1088147

51. Reddy, P. V.; Smith, J.; Kamath, A.; Jamet, H.; Veyron, A.; Koos, P.; Philouze, C.; Greene, A. E.; Delair, P. J. Org. Chem. 2013, 78, 4840-4849.

https://doi.org/10.1021/jo400386f

52. Smith, J.; Kamath, A.; Greene, A. E.; Delair, P. Synlett 2014, 25, 209-212.

https://doi.org/10.1055/s-0033-1340107

53. Kurono, N.; Ohkuma, T. ACS Catal. 2016, 6, 989-1023.

https://doi.org/10.1021/acscatal.5b02184

54. Grundke, C.; Opatz, T. Green Chem. 2019, 21, 2362-2366.

https://doi.org/10.1039/C9GC00720B

55. Liu, Y.-L.; Yin, X.-P.; Zhou, J. Chin. J. Chem. 2018, 36, 321-328.

https://doi.org/10.1002/cjoc.201800001

56. Jin, C.; Fix, S. E.; Kepler, J. A.; Cook, C. E. Bioorg. Med. Chem. Lett. 2012, 22, 1705-1708.

https://doi.org/10.1016/i.bmcl.2011.12.110

57. Palani, A.; Shapiro, S.; Josien, H.; Bara, T.; Clader, J. W.; Greenlee, W. J.; Cox, K.; Strizki, J. M.; Baroudy, B. M. J. Med. Chem. 2002, 45, 3143-3160.

https://doi.org/10.1021/jm0200815

58. Ting, P. C.; Umland, S. P.; Aslanian, R.; Cao, J.; Garlisi, C. G.; Huang, Y.; Jakway, J.; Liu, Z.; Shah, H.; Tian, F.; Wan, Y.; Shih, N.-Y. Bioorg. Med. Chem. Lett. 2005, 15, 3020-3023. 
https://doi.org/10.1016/j.bmcl.2005.04.054

59. Das, D.; Richers, M. T.; Ma, L.; Seidel, D. Org. Lett. 2011, 13, 6584-6587.

https://doi.org/10.1021/ol202957d

60. Trost, B. M.; Spagnol, M. D. J. Chem. Soc., Perkin Trans. 1 1995, 2083-2096.

https://doi.org/10.1039/p19950002083

61. Fantinati, A.; Bianco, S.; Guerrini, R.; Salvadori, S.; Pacifico, S.; Cerlesi, M. C.; Calo, G.; Trapella, C. Sci. Rep. 2017, 7, 1-7.

https://doi.org/10.1038/s41598-017-02502-9

62. Schunk, S.; Linz, K.; Frormann, S.; Hinze, C.; Oberbörsch, S.; Sundermann, B.; Zemolka, S.; Englberger, W.; Germann, T.; Christoph, T.; Kögel, B.-Y.; Schröder, W.; Harlfinger, S.; Saunders, D.; Kless, A.; Schick, H.; Sonnenschein, H. ACS Med. Chem. Lett. 2014, 5, 851-856.

https://doi.org/10.1021/ml500116x

63. Bertron, J. L.; Seto, M.; Lindsley, C. W. ACS Chem. Neurosci. 2018, 9, 2459-2474. https://doi.org/10.1021/acschemneuro.8b00266

64. Patterson, S.; Jones, D. C.; Shanks, E. J.; Frearson, J. A.; Gilbert, I. H.; Wyatt, P. G.; Fairlamb, A. H. ChemMedChem 2009, 4, 1341-1353.

https://doi.org/10.1002/cmdc.200900098

65. Thoma, G.; Beerli, C.; Bigaud, M.; Bruns, C.; Cooke, N. G.; Streiff, M. B.; Zerwes, H.-G. Bioorg. Med. Chem. Lett. 2008, 18, 2000-2005. https://doi.org/10.1016/j.bmcl.2008.01.108

66. Reimann, E.; Ettmayr, C. Monatsh. Chem. 2004, 135, 1289-1295. https://doi.org/10.1007/s00706-004-0204-8

67. Reimann, E.; Ettmayr, C.; Polborn, K. Monatsh. Chem. 2004, 135, 557-579. https://doi.org/10.1007/s00706-003-0136-8

68. Reimann, E.; Ettmayr, C. Monatsh. Chem. 2004, 135, 1143-1155. https://doi.org/10.1007/s00706-004-0184-8

69. Wasserman, H. H.; Dion, R. P.; Fukuyama, J. M. Heterocycles 1989, 28, 629-631. https://doi.org/10.3987/COM-88-S92

70. Zhu, J.; Quirion, J.-C.; Husson, H.-P. Tetrahedron Lett. 1989, 30, 5137-5140. https://doi.org/10.1016/S0040-4039(01)93468-9

71. Zinnes, H.; Comes, R. A.; Shavel, J., Jr. J. Org. Chem. 1965, 30, 105-112. https://doi.org/10.1021/j001012a026

72. Kudzma, L. V.; Spencer, H. K.; Severnak, S. A. Tetrahedron Lett. 1988, 29, 6827-6830. https://doi.org/10.1016/S0040-4039(00)88451-8

73. Ma, J.; Vannam, R.; Terwilliger, D. W.; Peczuh, M. W. Tetrahedron Lett. 2014, 55, 4255-4259. https://doi.org/10.1016/j.tetlet.2014.05.081

74. Schneider, C.; Börner, C. Synlett 1998, 652-654. https://doi.org/10.1055/s-1998-1725

75. Schneider, C.; Börner, C.; Schuffenhauer, A. Eur. J. Org. Chem. 1999, 3353-3362. https://doi.org/10.1002/(SICl)1099-0690(199912)1999:12<3353::AID-EJOC3353>3.0.CO;2-Q

76. Bernardi, L.; Bonini, B. F.; Capitò, E.; Dessole, G.; Fochi, M.; Comes-Franchini, M.; Ricci, A. Synlett 2003, 1778-1782.

https://doi.org/10.1055/s-2003-41471

77. Suginome, M.; Yamamoto, A.; Ito, Y. Chem. Commun. 2002, 1392-1393. 
https://doi.org/10.1039/b203645b

78. Le Gall, E.; Gosmini, C.; Troupel, M. Tetrahedron Lett. 2006, 47, 455-458.

https://doi.org/10.1016/j.tetlet.2005.11.070

79. Donald, J. R.; Wood, R. R.; Martin, S. F. ACS Comb. Sci. 2012, 14, 135-143.

https://doi.org/10.1021/co2002087

80. Donald, J. R.; Martin, S. F. Org. Lett. 2011, 13, 852-855.

https://doi.org/10.1021/ol1028404

81. Katritzky, A. R.; Manju, K.; Singh, S. K.; Meher, N. K. Tetrahedron 2005, 61, 2555-2581.

https://doi.org/10.1016/j.tet.2004.12.018

82. Katritzky, A. R.; Najzarek, Z.; Dega-Szafran, Z. Synthesis 1989, 66-69.

https://doi.org/10.1055/s-1989-27156

83. Katritzky, A. R.; Nair, S. K.; Qiu, G. Synthesis 2002, 199-202.

https://doi.org/10.1055/s-2002-19801

84. Katritzky, A. R.; Jurczyk, S.; Rachwal, B.; Rachwal, S.; Shcherbakova, I.; Yannakopoulou, K. Synthesis 1992, 1295-1298.

https://doi.org/10.1055/s-1992-26362

85. Katritzky, A. R.; Yang, H.; Singh, S. K. J. Org. Chem. 2005, 70, 286-290.

https://doi.org/10.1021/jo048541k

86. Prashad, M.; Liu, Y.; Har, D.; Repic, O.; Blacklock, T. J. Tetrahedron Lett. 2005, 46, 5455-5458.

https://doi.org/10.1016/j.tetlet.2005.06.066

87. Zarantonello, P.; Bettini, E.; Paio, A.; Simoncelli, C.; Terreni, S.; Cardullo, F. Bioorg. Med. Chem. Lett. 2011, 21, 2059-2063.

https://doi.org/10.1016/j.bmcl.2011.02.009

88. Abiero, A.; Botanas, C. J.; Custodio, R. J.; Sayson, L. V.; Kim, M.; Lee, H. J.; Kim, H. J.; Lee, K. W.; Jeong, Y.; Seo, J.-W.; Ryu, I. S.; Lee, Y. S.; Cheong, J. H. Psychopharmacology 2020, 237, 757-772.

https://doi.org/10.1007/s00213-019-05412-y

89. Liu, Y.; Prashad, M.; Shieh, W.-C. Org. Process Res. Dev. 2014, 18, 239-245.

https://doi.org/10.1021/op400250s

\section{Author's Biography}

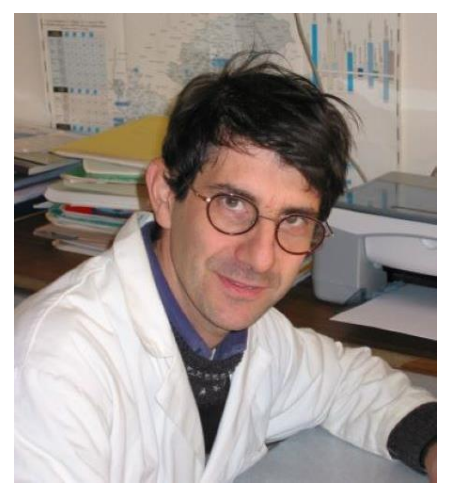

Jean-Marc Mattalia received his PhD in 1992 at the Faculty of Saint-Jérôme in Marseille under the supervision of Professor Michel Chanon. After postdoctoral studies in the group of Prof C.J.M. Stirling at the University of 
Sheffield, he joined the Aix-Marseille University as assistant professor. His research interests focus on reactivity and mechanism determinations in organic reactions. After experimental studies mainly on the Grignard reagent formation and the reductive decyanation reaction, his work now uses a molecular modelling approach.

This paper is an open access article distributed under the terms of the Creative Commons Attribution (CC BY) license (http://creativecommons.org/licenses/by/4.0/) 